\title{
Network of Advisors Enhances MRS Bulletin's Link to Materials Community
}

The MRS Bulletin's progress from a small newsletter in 1975 to its present format has followed the evolution of materials research, shaped by many individuals in the field. Among those who have contributed to the MRS Bulletin's progress in recent years are the Bulletin's associate editor in Europe, Ian W. Boyd, and three advisory groups-the International Advisory Board, the Technical Editorial Board, and the MRS Bulletin Publications Subcommittee-all led by chairman Elton N. Kaufmann. This network of consultants cuts across geographic borders and scientific disciplines to enhance the flow of information to the MRS Bulletin, each providing a personal point of contact with the members of the materials community.

Current board members come from Australia, China, Europe, India, Japan, and the United States. Their technical expertise touches every area of materials research, spanning fundamental and theoretical aspects, research and development, and manufacturing. Some of the MRS Bulletin's advisors focus on biomaterials, catalysts, or porous materials. Others concentrate on ceramics, composites, intermetallics, magnetic materials, and metals and alloys. The diversity of their scientific interests further extends to such areas as nanostructures, nuclear waste, computer modeling, diamond films, optical and electronic materials, and superconductors.

They bring experience with academia, the industrial environment, government research, and science policy-making bodies. They are involved in cooperative research across institutional lines and with international technical exchanges. Many of them are associated with other scientific publications and maintain memberships in professional societies related to chemistry, physics, metallurgy, ceramics, and electrical, mechanical, and chemical engineering.

This network of experts is available to support the MRS Bulletin in expanding and evaluating content, in selecting guest editors and authors, and in promoting a global perspective on materials research. The members of these groups also solicit proposals for theme issues, seek out Up Close and technical features, and alert the MRS Bulletin about conferences and news of potential interest to its readers.
The following biographical sketches briefly introduce the members of the MRS Bulletin's advisory team. You are invited and encouraged to contact them with suggestions and comments about how the $M R S$ Bulletin can continue to serve the interests of its readers.

\section{Associate Editor-Europe}

Ian W. Boyd, the MRS Bulletin's associate editor in Europe, is currently professor of electronics at University College London, having previously obtained a first-class honors degree in applied physics and a $\mathrm{PhD}$ in laser physics at Heriot-Watt University in Scotland. Boyd joined the faculty at the University of California-Los Angeles in 1984 after two years of postdoctoral research on picosecond phenomena in semiconductors at the University of North Texas. His research has centered on photon interactions with matter, from fundamental studies to applications in device technology. Recently, he has focused on uv- and vuv-induced surface modification and the growth of a wide variety of dielectric and superconductor structures.

Boyd is the author of the book, Laser Processing of Thin Films and Microstructures, and editor of seven others in the area of beam processing. He has published more than 140 papers and presented some 25 invited papers at international conferences. He currently runs a research group of 12 people.

Boyd is a fellow of the Institute of Physics and a Chartered Engineer. He currently serves on the executive committee of the European Materials Research Society (E-MRS) and has been an active member of its board of delegates for the past six years. Since 1990 he has been second vice president of E-MRS. In 1994, he was overall chairman for the E-MRS Spring Meeting. Boyd also serves as an EMRS representative to the International Union of Materials Research Societies. Ian W. Boyd, University College London, Dept. of Electronic and Electrical Engineering, Torrington Place, London WCr E7 JE, United Kingdom.

\section{Chairman-Editorial Boards}

Elton N. Kaufmann, chair of the $M R S$ Bulletin Editorial Boards since 1986, is associate director of the Strategic Planning

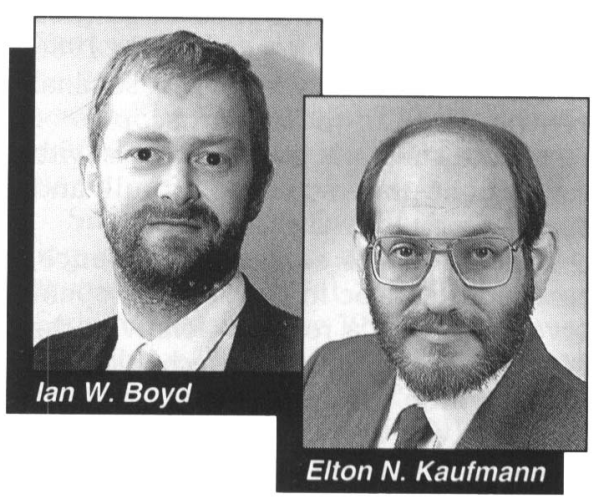

Group, Office of the Director, at Argonne National Laboratory, where he manages Argonne's laboratory-directed research and development program.

Prior to joining Argonne in 1989 as director of its Pilot Center for the Commercialization of Superconductivity, Kaufmann held several positions at Lawrence Livermore National Laboratory (LLNL), including leader of the Materials Division. At LLNL he studied materials processing, using energetic beams, and managed various applied and basic research programs. Kaufmann also worked for 13 years at Bell Telephone Laboratories in Murray Hill, New Jersey, where he pursued research on particlesolid and hyperfine interactions and their application to materials characterization.

Kaufmann has served as the editor of two books and the international journal, Hyperfine Interactions. He is currently editor of Annual Review of Materials Science. He has published more than 100 papers on nuclear physics, hyperfine interactions, ion-solid interactions, and laser- and electron-beam processing.

A physics graduate of Rensselaer Polytechnic Institute, Kaufmann received his PhD degree in physics from the California Institute of Technology. He is a fellow of the American Physical Society and a former president and councillor of the Materials Research Society, and currently chairs the MRS Committee on Public Affairs.

Elton N. Kaufmann, Associate Director,

Strategic Planning Group, Office of the Director, OTD/201, Argonne National Laboratory, 9700

South Cass Avenue, Argonne, IL 60439-4832. 


\section{International Advisory Board}

Minko Balkanski has pioneered, or made significant contributions to, numerous areas of research. His early explorations of photons, phonons, and photoemissions helped pioneer the area of Raman scattering in semiconductors and greatly influenced the field of surface physics. Balkanski received the 1986 MRS Von Hippel Award for his "seminal contributions to the spectroscopies of semiconducting and other materials with consequent understanding of bulk and surface structure and excitations."

Balkanski was educated in France, receiving his DSc in physics. He spent several years as a research fellow at the Massachusetts Institute of Technology in Prof. Arthur von Hippel's laboratory, where he was introduced to the concept of interdisciplinary materials research. Back in France, he was instrumental in the creation of laboratories at Ecole Normale Supérieure and at Université Pierre et Marie Curie that are considered to be among the world's best in materials science. Throughout his career, Balkanski has consistently chosen highly relevant and creative approaches to particular problems, bringing interdisciplinary talents to bear on his research projects.

Former director of the Solid State Physics Laboratory and Dean of International Affairs, Balkanski is now professor of physics at the University Pierre et Marie Curie, Paris. He serves as a scientific consultant in both France and the United States, and is a member of the editorial boards of several journals and the author or editor of 16 books and more than 600 publications.

Minko Balkanski, University of Pierre and Marie Curie Laboratoire de Physique des Solides, 4 Place Jussieu, Tour 13, 75230 Paris, Cédex 05, France.

Robert G. Elliman focuses his work on semiconductor materials research, with an emphasis on ion beam modification and analysis, a subject on which he has published more than 100 scientific papers. Areas of particular interest have included ion-beam-induced phase transformations, ion-beam-induced adhesion of thin films, ion-beam-induced electrical isolation in III-V semiconductors and, more recently, ion-beam processing and synthesis of $\mathrm{Ge}_{\mathrm{x}} \mathrm{Si}_{1-\mathrm{x}} / \mathrm{Si}$ heterostructures.

Elliman is senior fellow in the Department of Electronic Materials Engineering at Australian National University (ANU) in Canberra, where he heads an ion beam group. A 1983 PhD graduate of Salford University, England, he spent five years at the CSIRO Division of Chemical Physics in Australia, then moved to Melbourne to take a position as associate director of the Microelectronics and Materials Technology Centre, Royal Melbourne Institute of Technology. He joined ANU in 1990.

Robert J. Elliman,

Department of Electronic Materials Engineering, Research School of Physical Sciences and Engineering, Australian National University, GPO Box 4, Canberra, ACT 2601, Australia.

Shu-en Hsu has served since 1983 as director, Materials Research and Development Center, Chung Shan Institute of Science and Technology, Taiwan, where he directs a staff of 500 , including $60 \mathrm{PhDs}$. Hsu is also an adjunct professor at the Institute of Materials Engineering, National Taiwan University in Taipei. His areas of specialization include defense-oriented advanced materials, including superalloys, intermetallics, ceramics, high-temperature composites, sensors, and high-temperature superconductors.

The recipient of five awards for distinguished scientific achievement, Hsu has co-authored/edited four technical books and 120 technical papers and is the holder of seven Taiwanese patents. He was educated in the United States at Northwestern and Stanford universities, where he received $\mathrm{MS}$ and $\mathrm{PhD}$ degrees, respectively.

Shu-en Hsu, Chung Shan Institute of Science and Technology, P.O. Box 90008, Lung-Tan, Taiwan, ROC.

Louis C. Ianniello, currently a science and technology consultant, was until 1993 acting associate director and deputy director of energy research for Basic Energy Sciences (BES), U.S. Department of Energy. As such, Ianniello served as manager and principal spokesperson for the largest civilian research and development program in DOE. Ianniello originally joined BES in 1974 as branch chief for metallurgy and ceramics, Materials Sciences Division, and after that created and headed numerous basic science programs in such areas as materials sciences, energy sciences, biosciences, engineering chemical sciences, geosciences, and advanced energy projects.
He initiated, planned, and implemented the program for the Superconducting Super Collider, and led the DOE effort in coordinating such technical projects as high-temperature superconductivity. Throughout his career with BES, Ianniello worked aggressively to promote and improve DOE's materials program. He is the recipient of numerous honors, including the Presidential Meritorious Rank Award for Outstanding Performance (1988), the DOE Special Achievement Award (1988), and the DOE Bronze Medal for Exceptional Service (1986).

Prior to joining BES, Ianniello did metallurgical research at Argonne National Laboratory, then at the Atomic Energy Commission's Physical Research Division. He received his $\mathrm{PhD}$ in physical metallurgy from Rensselaer Polytechnic Institute.

Louis C. lanniello, 20006 Holly Pond Way, Gaithersburg, MD 20879.

Heng-De Li began his teaching and research career in Beijing, China in 1955 when he joined the Materials Science and Engineering staff of Tsinghua University. $\mathrm{Li}$ is a professor in the Materials Science and Engineering Department and, since 1979 , has served as director of that department's interdisciplinary Research Institute. $\mathrm{He}$ is also director of the Department of Materials and Engineer- 


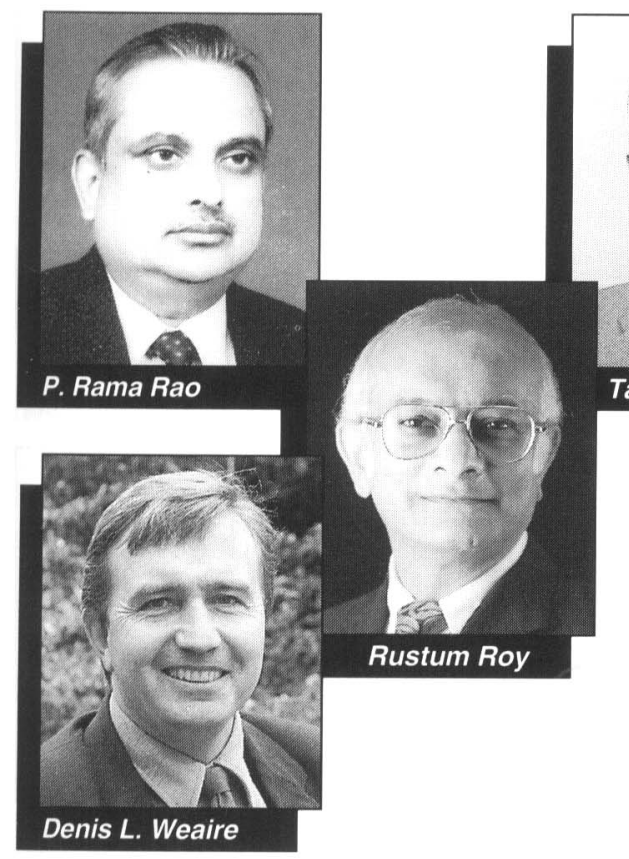

ing Sciences of the National Natural Science Foundation of China.

A graduate of National Northwestern College of Engineering (China), Li received his MS degree from Carnegie Institute of Technology (Pittsburgh, Pennsylvania) and his PhD degree from the University of Pennsylvania. $\mathrm{He}$ is experienced in the field of nuclear materials; his research interests center on ion beam modification of metals, bioceramics, and electronic packaging materials.

$\mathrm{Li}$ is president of the Chinese Materials Research Society and in 1993 initiated the IUMRS-ICA serial conference. He also serves on various national committees in China, including the National Graduate Degree Evaluation Committee and the Key Lab Evaluation Committee.

Heng-De Li, National Science FoundationChina, 35 North Hua-Yuan Road, Beijing 100083, China.

P. Rama Rao holds two positions with the government of India: secretary, Department of Science and Technology, and secretary, Department of Ocean Development. He is also an honorary professor at the Jawaharlal Nehru Centre for Advanced Scientific Research.

A scientist whose interests revolve around alloy development and the strength and fracture of materials, Rao has received numerous awards for his work, including the 1992 Tata Gold Medal from the Indian Institute of Metals, the 1990 Distinguished Alumnus Award from the Indian Institute of Science, and the 1989 Materials Science Prize from the Indian National Science Academy.

Rao is a graduate of the University of Madras, India, and received his MSc degree from Andhra University and his PhD degree from Banaras Hindu University. He is president of the Materials Research Society of India and holds numerous other honorary affiliations, including Foreign Member, The Royal Academy of Engineering, United Kingdom; Fellow, Indian Academy of Sciences; and Fellow, National Academy of Sciences, India.

P. Rama Rao, Director, Department of Science \& Technology, Secretary to the Government of India, Technology Bhavan New Mehrauli Road, New Delhi-110016, India.

Rustum Roy is Evan Hugh Professor of the Solid State and professor of geochemistry at Pennsylvania State University. $\mathrm{He}$ is creator and director of the university's Science, Technology, and Society Program, and has been active in science policy matters at the state and federal levels through service on a wide range of committees.

The author or co-author of five books and more than 500 papers, Roy is noted for his work in the science of preparing new materials, particularly in sol-gel science, the second generation of diphasic gels leading to nanocomposites, and phase diagrams. Roy started the Materials Research Bulletin and initiated the Materials Education Council and what is now the Journal of Materials Education. He received his BS and MS degrees in chemistry from Patna University in India and a PhD in ceramics from Penn State. Roy was one of the founders of MRS and also its first elected vice president. He also served MRS as president in 1977.

Rustum Roy, Materials Research Laboratory, Pennsylvania State University, University Park, PA 16802.

Takuo Sugano focuses his research on the physics and technology related to semiconductor nanoelectronics. His work in this area includes the fabrication technology of nanostructures (such as quantum wires and dots), characterization of their electrical and optical properties, and the application of nanostructures to elec- tron and photon devices.

During his long tenure at the University of Tokyo, where he is professor emeritus (electronic engineering), Sugano conducted extensive research on the physics and technology of metalinsulator-semiconductor devices, particularly Si MOS devices, and $\mathrm{GaAs}$ and InP devices. He has authored or co-authored several books on semiconductor electronics and has more than 200 papers and numerous patents and awards to his name.

Sugano is dean, Faculty of Engineering, and professor of electrical and electronic engineering at Toyo University, Saitama, Japan. Since 1991 he has served as director, Frontier Materials Research Group, Institute of Physical and Chemical Research (RIKEN). Sugano received his bachelor's, master's, and doctoral degrees in engineering from the University of Tokyo.

Takuo Sugano, Toyo University, Department of Electrical and Electronic Engineering, 2100 Nakanodai, Kujirai, Kawagoe, Saitama 350 , Japan.

Denis L. Weaire, a solid-state theorist and computational physicist, holds the title Erasmus Smith Professor of Natural and Experimental Philosophy at Trinity College, Dublin, Ireland. Weaire's current research centers on the emerging science of foams and has already yielded significant results. In a collaborative effort with postgraduate student Robert Phelan, Weaire produced a structure refuting Kelvin's classic conjecture on minimal surfaces. Weaire's counter example is based on two cell types, one 14-sided and one 12-sided. Weaire is also well-known for his early work on amorphous silicon, which illuminates various key issues such as the existence of a bandgap in such a disordered material. $\mathrm{He}$ is the author or co-author/co-editor of four books and more than 180 papers in his field.

Born in India, Weaire was educated in Northern Ireland, England, and at several major universities in the United States, including Harvard, Yale, and the University of California-Berkeley. He received his $\mathrm{BA}$ degree in mathematics and his PhD degree in physics from the University of Cambridge, England.

A fellow of Trinity College and a member of the Royal Irish Academy, Weaire is deeply involved in cooperative scientific programs with the European Community. Denis L. Weaire, University of Dublin, Trinity College, Physics Department,

Dublin 2, Ireland. 


\section{Technical Editorial Board}

John C. Bravman is an associate professor and associate chairman in the Department of Materials Science and Engineering at Stanford University. He is also associate dean for student affairs in the School of Engineering. His research interests focus on the processing and analysis of thin-film materials and structures. He directs doctoral students in the areas of silicon and gallium arsenide process technology, high-temperature superconductivity, the mechanical properties of thin films, and transmission electron microscopy.

Bravman is a graduate of Stanford University, where he received BS, MS, and $\mathrm{PhD}$ degrees in materials science. After completing his studies at Stanford, he worked at the Fairchild Semiconductor Research and Development Laboratories, Palo Alto, California, and has consulted at several Silicon Valley firms. He joined the Stanford faculty in 1985.

Active in many phases of teaching, research, and student advising, Bravman has received numerous science education awards, including the Walter J. Gores Award, Stanford's highest excellence-inteaching award. He received ASM International's 1991 Bradley Stoughton Award for Young Teachers and the 1992 Excellence in Teaching Award from the Society of Women Engineers. He has coauthored 90 research publications.

Currently president of the Materials Research Society, Bravman has served MRS in many capacities. He was an MRS councillor, co-chaired the 1990 MRS Spring Meeting, organized several symposia, and served on several committees. John C. Bravman, Department of Materials Science and Engineering, Stanford University, Building 550, Stanford, CA 94305-2205.

Clifton W. Draper is a Distinguished Member of the Technical Staff of AT\&T Bell Laboratories Engineering Research Center, Princeton, New Jersey, where he has worked for 16 years in various research, technical, and project management areas. Currently, his research focuses on the improvement of chemical and cleaning processes in manufacturing lines; he has also worked on glass fabrication processes, light-guide glass manufacture, laser-surface interactions, rapid solidification, and surface alloying.

A graduate of the State University of New York at Albany, Draper received his $\mathrm{PhD}$ degree in physics from Pennsylvania State University. He is the editor of one book, the author or co-author of more than 70 technical publications, and the holder of two patents. Draper has been active in
NATO science programs-serving as NATO/AGARD Consultant in Portugal in 1988-and serves on the peer review panel for the New Jersey State Commission on Science and Technology.

Actively involved in MRS since 1978, Draper co-chaired the 1988 MRS Spring Meeting, served as MRS treasurer in 1985-1986, and chaired the Finance and Corporate Participation committees. He is currently an MRS councillor.

Clifton W. Draper, AT\&T ERC, P.O. Box 900, Princeton, NJ 08542-0900.

Eric Fogarassy is director of research, Centre National de la Recherche Scientifique (CNRS), where he leads the Laser Materials Processing Group at the Laboratoire de Physique et Applications des Semiconducteurs (PHASE) in Strasbourg, France. His research involves various areas of excimer laser surface modifications and uv-photoassisted thinfilm deposition of insulators, semiconductors, and high $\mathrm{T}_{\mathrm{c}}$ compounds. He has organized several international conferences on these topics and is the co-author of more than 100 scientific articles and the holder of several patents.

Fogarassy was born in Paris and studied at Université Pierre et Marie Curie, where he received a doctor of materials science degree. He worked for two years at the Philips Laboratories in Paris and taught solid-state physics at the University of Tunis in Tunisia before joining CNRS in 1978.

A member of the Board of Delegates of the European Materials Research Society, Fogarassy is active in many French and European scientific programs and, in his work, collaborates with numerous French industrial groups.

Eric Fogarassy, CRN, Laboratoire PHASE, 23 rue du Loess, B.P. 20, Strasbourg, Cédex 67037, France.

Frank Y. Fradin is associate laboratory director for physical research at Argonne National Laboratory, where he is responsible for an annual program of research and development in chemistry, materials sciences, mathematics and computer science, and high energy and nuclear physics. His group comprises more than $450 \mathrm{PhDs}$ and a support staff of 100 . His areas of research specialization include superconductivity and magnetic materials.
Fradin has been a visiting professor at Northern Illinois and Northwestern Universities, and has served on government advisory panels and on advisory boards for companies and educational institutions, as well as on organizing committees for many international conferences. He is also a fellow of the American Physical Society.

Fradin graduated from the Massachusetts Institute of Technology and received his $\mathrm{PhD}$ degree from the University of Illinois at Urbana. He joined Argonne in 1967.

Frank Y. Fradin, Associate Laboratory Director for Physical Research, Building 221, Argonne National Laboratory, 9700 South Cass Avenue, Argonne, IL 60439-4844.

Betty M. León is a full professor in the Applied Physics Department of the University of Vigo, Spain. She received her Diplom physiker from the Technical University of Aachen, Germany, and her PhD from Universidad Complutense, Madrid, Spain.

Trained as a solid-state physicist, León has worked in such fields as optical properties of solids, semiconductor technology, and electrooptical effects in liquid crystals. In all of these areas, she has concentrated on their potential applications to industrial problems. During the past 10 years, León has been a pioneer in the field of laser processing in Spain, focusing on laser-induced CVD of dielectric and 

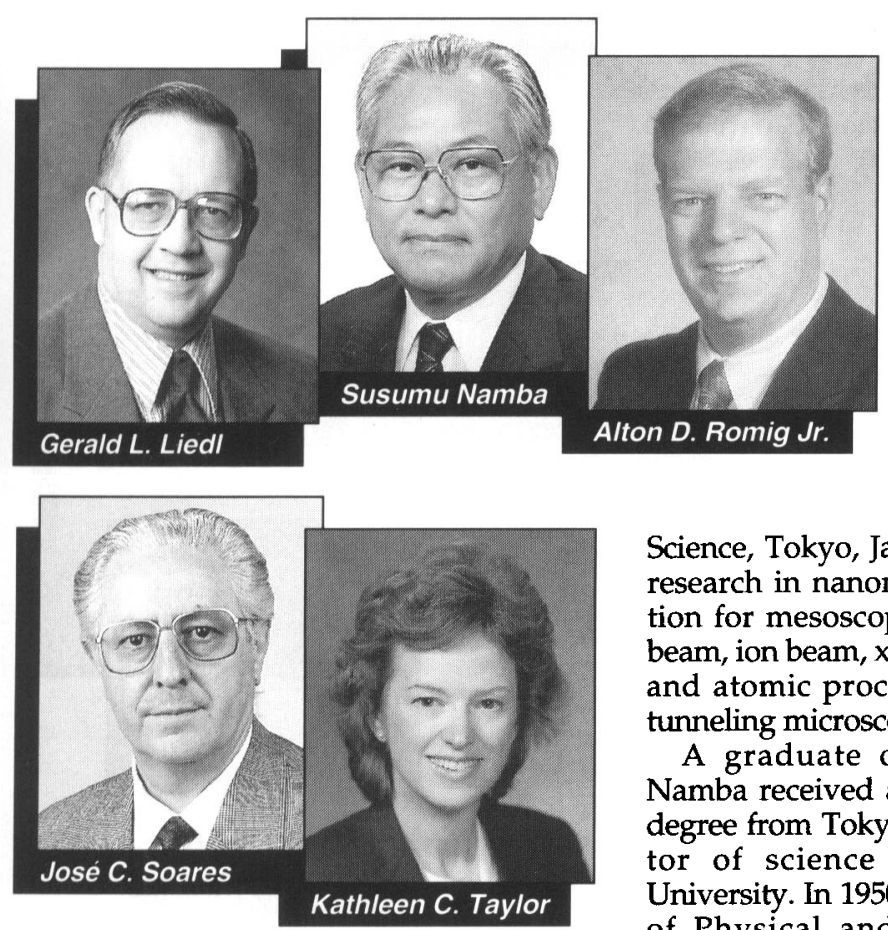

ceramic materials. She is the author of more than 40 scientific and technical papers.

Since 1987, León has served as Spanish correspondent for the European Materials Research Society (E-MRS), actively promoting the participation of Spanish and European groups in E-MRS and stimulating closer contact among them.

Betty M. León, Depto. Fisica Aplicada, Universidad de Vigo, Lagdas-Marcosende, 9 , 36280 , Vigo, Spain.

Gerald L. Liedl, a graduate of Purdue University, where he received his BS and PhD degrees, is now professor and head of Purdue's School of Materials Engineering. Since joining the university's faculty in 1958, Liedl has focused his research on structural characterization of materials, and worked toward developing new directions in materials education. He is involved in numerous research coordination activities as director of MATRIX, a four-university synchrotron $x$-ray scattering group, and as the developer of MISCON, a six-university consortium to encourage research in high-temperature superconductors.

Liedl is a fellow of ASM International and a member of the Engineering Accreditation Commission of the Accreditation Board for Engineering and Technology; he chairs the committee for accrediting materials and metallurgical education programs of The Minerals,
Metals, and Materials Society and is a founding member and past chair of the University Materials Council.

Gerald L. Liedl, Purdue University, 1289 MSEE Building, West Lafayette, IN 47907-1289.

Susumu Namba is a professor at Nagasaki Institute of Applied Science, Tokyo, Japan, where he pursues research in nanometer structure fabrication for mesoscopic devices by electron beam, ion beam, x-ray, and excimer lasers; and atomic processing using scanning tunneling microscopy.

A graduate of Osaka University, Namba received a doctor of engineering degree from Tokyo University and a doctor of science degree from Kyoto University. In 1950 he joined The Institute of Physical and Chemical Research (RIKEN) and since 1966 has served as chief researcher of the Semiconductor Laboratory and Laser Science Laboratory, and as director of the Materials Group of RIKEN's International Frontier Research System. From 1967 to 1991, Namba was a professor of electronic engineering at Osaka University.

Namba has been honored with two Japanese national science awards: the Prize of the Minister of Science and Technology in 1973 and, in 1988, the Emperor of Japan Medal of Honor with Purple Ribbon.

Susumu Namba, Nagasaki Institute of Applied Science, 4-8-5 Nakaochiai, Shinjuku-ku, Tokyo 161, Japan.

Alton D. Romig Jr. is director of materials and processes sciences at Sandia National Laboratories, Albuquerque, New Mexico, where he pursues both research and technology interests: high spatial resolution $x$-ray microanalysis, solid-state diffusion (modeling), and phase stability; materials for electronic packaging, including soldering and microwelding; and the reliability of integrated circuit interconnect metallizations.

Romig is a graduate of Lehigh University, with BS, MS, and PhD degrees in materials science and engineering. The author or co-author of more than 130 technical papers on physical metallurgy and microanalysis, and the co-author of three textbooks on electron microscopy, he holds two U.S. patents, one involving an advanced spectroscopic technique, and one regarding enhanced reliability of aluminum interconnect metallizations.

Romig is the 1988 winner of the Burton Medal of the Microscopy Society of America, recipient of the 1991 K.F.J. Heinrich Award as Outstanding Young Scientist under 40 , and a fellow and trustee of ASM International. In 1992, he was awarded the ASM-MSD Materials Science Division Research Award as an outstanding materials research scientist. Romig is the 1993-94 Acta Metallurgica International Lecturer and a short course lecturer for the Materials Research Society. Alton D. Romig Jr., Director, Materials and Process Sciences, Sandia National Laboratories, Organization 1800, P.O. Box 5800, Albuquerque, NM 87185.

José C. Soares was educated in Rome, Lisbon (Portugal), and Bonn (Germany) and holds degrees in philosophy, social sciences, and physics, as well as a Doktor der Naturwissenshaften. After receiving his PhD degree in physics from the University of Lisbon in 1969, he joined the university's Department of Physics. Over the course of his 24-year teaching and research career at Lisbon, he has held positions as auxiliary professor, then associate professor, and in 1989 was named Professor Agregado, Department of Physics and Nuclear Research Center.

Soares' current research interests include hyperfine interaction studies using radioactive isotopes, materials surface modification by high-fluence ion implantation, and materials characterization using ion beams. He is the author or co-author of more than 100 papers on research and science education and the coauthor/editor of two books.

Active in many projects involving science education, student exchanges, and bilateral cooperation in research, Soares helped organize the NATO School program for nuclear physics applications in materials science. He organized an E-MRS Symposium on Nuclear Methods in Semiconductor Physics. Soares serves as Portuguese Delegate to the European Materials Research Society, is a member of the Böhmische Physical Society, and is director of the Center for Processing and Characterization of New Materials, which he helped establish.

José $C$. Soares, Universidade de Lisboa, Centro de Fisica Nuclear, Av. Prof. Gama Pinto 2, 1699 Lisboa, Cedex, Portugal.

Kathleen C. Taylor is head of the Physical Chemistry Department at the General Motors North American Operations Research and Development Center, where 
she oversees research activities in catalysis, emissions control, corrosion science, advanced batteries, surface coatings, and chemical processes. Taylor joined General Motors in 1970, held supervisory positions in Physical Chemistry, and headed the Environmental Science department before being named to her current post in 1985 .

The author of numerous technical papers and a book on automobile catalytic convertors, Taylor was François Gault Lecturer in Catalysis in Europe. She received the 1989 Garvan Medal from the American Chemical Society.

Taylor was president of the Materials Research Society in 1987 and holds many other professional memberships. She is chair of the Board of Trustees of the Gordon Research Conferences, and chaired the Gordon Conference on Catalysis in June 1993. She is also a member of the board of directors of the North American Catalysis Society, the editorial board of the Journal of Catalysis, and the advisory board for Chemical and Engineering News. Taylor is also a member of the American Chemical Society, the National Materials Advisory Board, The Chemical Society (London, England), SAE International, and Sigma $X i$.

Kathleen C. Taylor, Physical Chemistry Department, NAO Res. \& Dev. Center, General Motors Corporation,

Warren, MI 48090-9055.

\section{Publications Subcommittee}

Aaron Barkatt is an associate professor in the Department of Chemistry at The Catholic University of America. His research interests include corrosion of glasses (natural, nuclear waste, and simple glasses), corrosion and surface chemistry of high $T_{c}$ superconducting materials, corrosion products of alloys in steam generator systems, and sol-gel chemistry in nonsilicate systems. Barkatt's current focus is building a program in the chemistry of materials at Catholic University.

Barkatt has chaired two MRS symposia: Materials Stability and Environmental Degradation (Spring 1988) and Scientific Basis for Nuclear Waste Management (Fall 1993). He is a member of the National Association of Corrosion Engineers. A graduate of Hebrew University of Jerusalem, where he received $\mathrm{BS}$ and $\mathrm{PhD}$ degrees in chemistry, Barkatt did postdoctoral research at Purdue University.

Aaron Barkatt, Department of Chemistry, Maloney Hall, Catholic University of America, Washington, DC 20064.

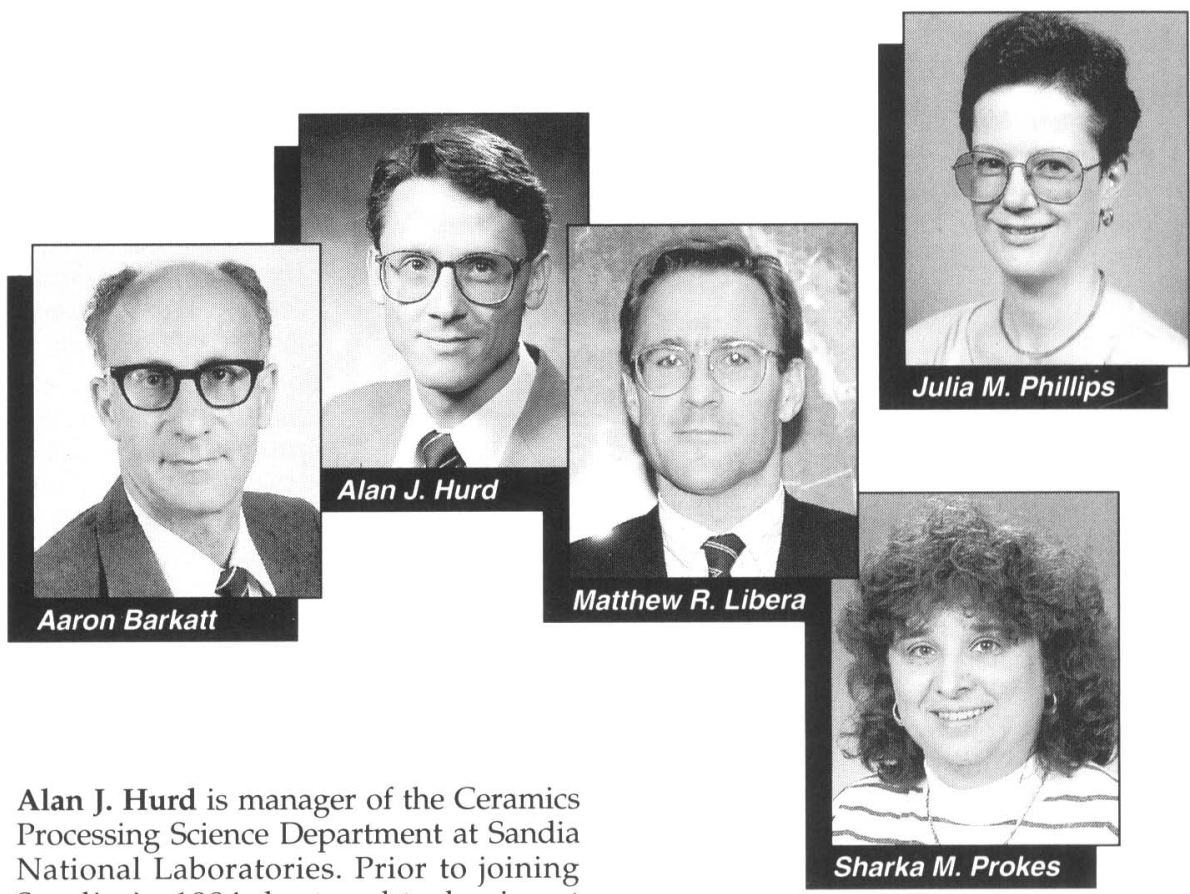

Sandia in 1984, he taught physics at Brandeis University, and also was an adjunct professor at the University of New Mexico.

Hurd holds several degrees in physics: a BS degree from the Colorado School of Mines and a PhD degree from the University of Colorado. His research interests include sol-gel processing, behavior of complex fluids, light scattering and small-angle scattering, and powder compaction. Among his honors is an award for Significant Implications in Ceramics and Metallurgy from the Department of Energy's Office of Basic Energy Science. Interested in K-12 science education, Hurd serves on curriculum development committees and is involved in Sandia's science education outreach.

Hurd has been áctive in MRS as a meeting chair, technical contributor, symposium organizer, and short course instructor. He chaired the 1994 MRS Spring Meeting, serves on the Publications Committee, and is a former vice president of the New Mexico Section. Alan J. Hurd, Department 1841, Sandia National Laboratories, P.O. Box 5800 , Albuquerque, NM 87185-5800.

Matthew R. Libera is an associate professor of materials science and engineering at the Stevens Institute of Technology, Hoboken, New Jersey, where he conducts research on phase transformations and microstructural evolution. Using the transmission electron microscope, he is developing and applying a variety of electron-optical imaging, diffraction, and spectroscopic techniques to solve microstructural problems in all classes of engineering materials. Libera is co-director of the Analytical Characterization Facility of the New Jersey Advanced Technology Center for Surface-Engineered Materials (ATC-SEM).

Prior to joining Stevens, Libera was a visiting scientist at the IBM Almaden Research Center, San Jose, California, studying thin films for optical data storage. He was a guest co-editor of the April 1990 MRS Bulletin issue on Optical Storage Disk Technology.

Active in MRS, Libera serves on the Publications and Membership Committees, and has chaired or co-chaired three symposia, the most recent being the 1993 MRS Fall Meeting symposium on Crystallization and Related Phenomena.

Libera graduated from the Massachusetts Institute of Technology with an $\mathrm{ScD}$ degree in materials science and received a 1986 MRS Graduate Student Award.

Matthew R. Libera, Department of Materials Engineering, Stevens Institute of Technology, Castle Point Station, Hoboken, NJ 07030. 


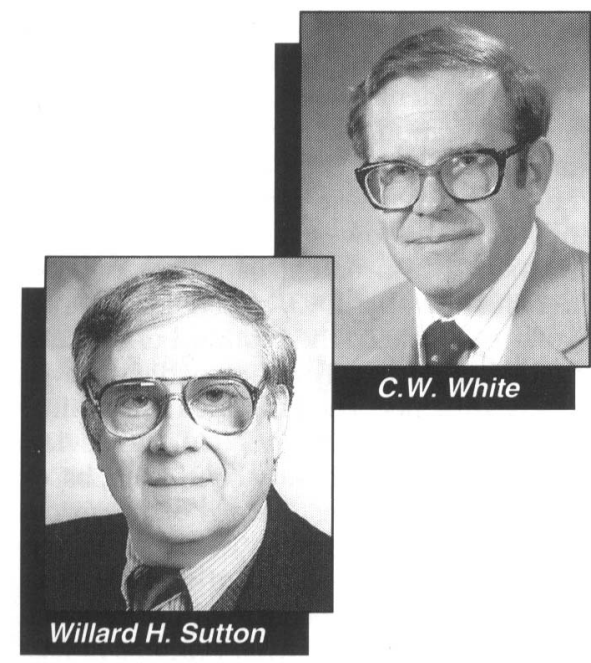

Julia M. Phillips is supervisor of the Thin Film Research Group at AT\&T Bell Laboratories and manager of the High $T_{c}$ Materials and Technology Program of the Consortium for Superconducting Electronics. Her research centers on heteroepitaxy, with a concentration in thinfilm growth of diverse materials, including high-temperature superconductors and other oxides.

Phillips' other interests include epitaxial insulators and metals on semiconductors, and structural and electrical characterization of these heterostructures; ion beam analysis; and application of rapid thermal processing techniques to heteroepitaxy.

A graduate of the College of William and Mary with a degree in physics, Phillips received a PhD degree in applied physics from Yale University. She is a principal editor of Journal of Materials Research and is on the editorial board of Applied Physics Letters/Journal of Applied Physics.

Phillips is MRS first vice president and president-elect and has served as second vice president (1993), as a councillor (1991-93), and as MRS secretary (1987-89). She chaired the 1991 MRS Fall Meeting, organized several MRS symposia, and has chaired a number of MRS committees, including the Program, Publicity and Public Relations, and Corporate Participation committees. Julia M. Phillips, AT\&T Bell Laboratories, Room 1D-158, 600 Mountain Avenue, Murray Hill, NJ 07974-2070
Sharka M. Prokes is a staff research scientist in electronic materials at the Naval Research Laboratory (NRL) where she researches optical and surface properties of porous silicon and other semiconductor nanostructures, growth of naturally occurring structures (such as two-dimensional wires on Si-stepped surfaces), and the effects of strain and dopant incorporation on interface roughening and interdiffusion in semiconductors.

Prokes graduated Phi Beta Kappa in physics from Northwestern University, then attended Harvard University, where she received SM and PhD degrees in applied physics. In 1986 she joined NRL as a postdoctoral fellow, doing research on MBE growth of IV-IV and III-V semiconductors. She was named to her current post in 1988. A former teaching fellow at Harvard, Prokes is now on the faculty of Johns Hopkins University and has been a mentor in NRL's Science and Engineering Apprentice Program.

Prokes is the author or co-author of 55 journal articles and conference proceedings papers and the holder of a patent. She has chaired two MRS meeting sessions and has given numerous invited presentations.

Sharka M. Prokes, Naval Research Laboratory, Code 6864, 4555 Overlook Avenue SW, Washington, DC 20375-5000.

Willard H. Sutton is a principal scientist at the United Technologies Research Center, where he is responsible for the activities of the Advanced Ceramics Group. He has made numerous contributions to the development of advanced fibers and metal- and ceramic-matrix composite materials. His achievements extend to the advanced melt processing of superalloys and range from the use of ceramic foam filters in lab experiments to full production.

Sutton has written more than 70 papers and is co-author of two books on advanced fibers and composites. He coorganized the first MRS symposium on Microwave Processing of Materials in 1988 , was guest editor for the November 1993 MRS Bulletin issue on Microwave Processing of Materials, and has coedited four books on this topic.

A graduate of Alfred University, Sutton received his $M S$ and $P h D$ degrees in ceramic technology from Pennsylvania State University. He is a fellow of the American Ceramic Society and a member of the National Research Council Committee on Microwave Processing of Materials. Willard $H$. Sutton, Mail Stop 24, United Technologies Research Center, Silver Lane, East Hartford, CT 06108.

C.W. White is now group leader of the Ion-Solid Interactions Group for Oak Ridge National Laboratory's Solid State Division. He previously worked at Bell Laboratories from 1967 to 1975.

White's research interests include ion implantation, laser annealing, ion beam analysis, ion beam modification of materials, and surface physics. He has more than 150 publications and eight patents to his credit. He served as a principal editor for Journal of Materials Research for five years and subsequently served on the JMR Advisory Review Board. He is also a former president and councillor of the Materials Research Society. White received his BS degree in physics from the Massachusetts Institute of Technology and a PhD degree in physics from Duke University.

C.W. White, Solid State Division, Building 3025, Oak Ridge National Laboratory,

Oak Ridge, TN 37831.

MTRS

\section{The MRS Bulletin values your opinion and invites you to write to the editor.} Please sign your letter, include your affiliation and let
us know how to contact you.

Mail or fax your letter to:
Editor, MRS Bulletin, Materials Research Society, 9800 McKnight Road, Pittsburgh, PA 15237-6006 FAX: (412) 367-4373 